\title{
OPTIMALITY AND EXISTENCE FOR LIPSCHITZ EQUATIONS
}

\author{
JOHNNY HENDERSON \\ Departinent of Algebra, Combinatorles, \& Analysis \\ Auburn Iniversity \\ Aubiurn, Llabama 36349
}

(Received January 5, 1987 and in revised form July 28, 1987)

ABSTRACT: Solutions of certain boundary value problems are shown to exist for the $n$th order differential equation $y^{(n)}=f\left(t, y, y^{\prime}, \ldots, y(n-1)\right.$, where $f$ is continuois on a slab $(a, b) \times R^{n}$ and $f$ satisfies a Lipschitz condition on the slab. nptinal length sublntervals of $(a, b)$ are deternined, in terns of the Lipschitz coefficlents, on which there exlst unliue solutions.

KEY WORDS AND PHRASES: Ordinary dIfferential equation, boundary value problen, Lipschitz condition, optimal length laterval, uniqueness imples extstence. 1980 AMS SUBJECT CLASSIFICATION: 34B10, $34 \mathrm{BL}$.

l. INTRODUCTION.

We will be concerned with the existence of solutions of boundary value problems for the nth order differential equation

$$
y^{(n)}=f\left(t, y, y^{\prime}, \ldots, y^{(n-1)}\right),
$$

where $f$ is continuous on a slab $(a, b) \times R^{n}$ and satisfies a Lipschitz condition,

$$
\left|f\left(t, y_{1}, \ldots, y_{n}\right)-f\left(t, z_{1}, \ldots, z_{n}\right)\right| \leq \sum_{1=1}^{n} k_{1}\left|y_{1}-z_{1}\right| \text {, }
$$

on the slab.

A number of papers have appeared in which optimal length subintervals of $(a, b)$ are determined, in terms of the Lipschitz coefficients $k_{1}, 1 \leq 1 \leq n$, on which solutions of certain boundary value problems for (1.1) are unique; see, for example [1-15]. Of motivational importance in this work are the papers by Jackson [10-11] In which he applied methods from control theory in establishing optimal length subintervals, in terms of the Lipschitz coefficients, on which solutions of confugate boundary value problems and right focal point boundary value problems for (1.1) are unique. It then follows from uniqueness implies existence results due to Hartman [16-17] and Klansen [18] in the conjugate case and Henderson [19] in the right focal point case, that unique solutions exist on the optimal intervals given in $[10-11]$. 
In [7-3], ve adapted Jackson's control theory argunents, In conjuncton with untifeness linplies exlstence resiltes, and deterintind ontinal length subintervils of $(a, b)$ on which there exlst inlque solutions of severil classes of bounitary value problens for thled and fourth order ordinary diffarential equations

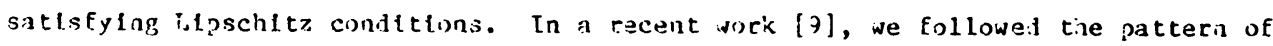
[7-9, 10-11], by applylnz the Pontryagla Maxinum Prinetple to a linearization of $(1.1)$, and deternined optinat length subintervals of $(a, b)$, in terns of $k_{1}$, on which solitions are unfiue for bouniary value problens for (1.1) satisfying

$$
\begin{array}{ll}
y^{(i)}\left(t_{i}^{\prime}\right)=y_{t+1}, & 0 \leq 1 \leq n-h+k-1, \\
y^{(1)}\left(t_{1}\right)=y_{n-h+(1+1)}, & k \leq 1 \leq h-1,
\end{array}
$$

where $n<t_{i}<t_{k} \leq \cdots \leq t_{h-1}<b, n \leq k<n \leq n$, and $y_{1} \varepsilon \quad R, 1 \leq 1 \leq n$.

In thls work, we now adiress the problem of exlstence of silutions of ( 1.1$)$, (1.3) on the optinal intervals for unliueness givei in [9]. We state in Section 2 some of the results concerning optimality and dinlqueness obtained in [9] which are pertinent to the argunent; here. Then in Section 3, we are able to prove that on subintervals of length less than the optimal length gligen in section 2 and for certain values of $k$ anil $h$, solitions of (1.1), (1.3) exist. For this restricted set of $k$ and $h$, the existence result is in sone sense analogous to the iniqueness inplies existence resilts in [15-19].

2. OPTIMALITT AND UNIQUJENESS.

In thls section, we state a Theorein and a Corollary froin [9, Thm. $3 \&$ the Cor.l, In Jhtcin optimal length subintervals of $(a, b)$ in terms of the Lipschitz coefficients $k_{1}, 1 \leq 1 \leq n$, are determined on which solutions of $(1.1)$, (1.3) are
unliue.

THEOREY 1. Let $n \leq k<h \leq n$ be glven and let $\gamma=m \ln \left\{\gamma_{\ell} \mid k \leq \ell<h\right\}$, where $r_{e}$ is the snilliast positive number such that there exlsts a solution $x(t)$ of the boundary value problen

$$
\begin{gathered}
x^{(n)}=(-1)^{h-l}\left[k_{1} x+\sum_{l=1}^{n} k_{1}\left|x^{(1-1)}\right|\right], \\
x^{(1)}(0)=0,0 \leq 1 \leq n-h+l-1, \\
x^{(1)}\left(\gamma_{p}\right)=0, \ell \leq 1 \leq h-1,
\end{gathered}
$$

with $x(t)>0$ on $\left(0, \gamma_{\ell}\right)$. or $\gamma_{\ell}=+\infty$ if no such solution exists. For any $k \leq \ell<h$, if $y(t)$ and $z(t)$ are ilstinct solutions of (1.1) such that

$$
\begin{gathered}
y^{(1)}\left(t_{1}^{\prime}\right)=z^{(1)}\left(t_{1}^{\prime}\right), 0 \leq 1 \leq n-h+l-1, \\
y^{(1)}\left(t_{1}\right)=z^{(1)}\left(t_{1}\right), l \leq 1 \leq h-1,
\end{gathered}
$$

$a<t_{1}^{\prime}<t_{0} \leq \cdots \leq t_{k-1}<b$, and if $h_{h-1}-t_{i}<\gamma$, it follows that $y(t) \equiv z(t)$ on $(a, b)$, and this 1 s best posstble for the class of all differential equations satisfying the ipscintz condition (l.?). 
REMARK. Jacksoil [1:! $u$ : , oved Theorem 1 for the case when $h=n$ and $k=0$.

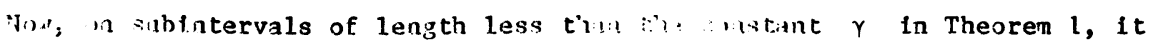
Eollows from Rolle's Theoren that solutions of a number of other inilla ralue probituls for (1.1) are unlque. For example, we can state the following.

COROLLARY 2. Let $\gamma$ be as la Thandil. " 1 any $k \leq \ell<h$ and $h-\ell \leq j \leq h$, if $y(t)$ and $z(t)$ are solutions of (l.1) such that

$$
\begin{aligned}
& y^{(1)}\left(t_{1}^{\prime}\right)=z^{(1)}\left(t_{1}^{\prime}\right), 0 \leq 1 \leq n-h+l-1, \\
& y^{(1+j-h)}\left(t_{1}\right)=y^{(1+j-h)}\left(t_{1}\right), l \leq 1 \leq h-1,
\end{aligned}
$$

$a<t_{1}^{\prime}<t_{\ell} \leq \cdots \leq t_{h-1}<b$, ant if ${ }_{h-1} i r$, it follows that $y(t) \equiv z(t)$ on $(a, b)$, and this is best posstintis:

3. EXISTENCE OF SOLUTLOV:

Analoguls $\because 11$ leness implies existence results proved by Hartman [16-17], Klaasen [18], and Henderso : 19], we give a proof In this section El: optinal subintervals for uniquenes: 1040101 la Section 2 and for a restricted at: of values of $h$ and $k$, the boundary vil.aphlems (1.1), (1.3) have unique $\therefore \therefore$ tions. For the proof, we use somewhat standard shooting methots. do $1: 1$ jive the proof only for two-point problems, with the plif for nultipoint problems being sinilar.

THEOREM 3. Let $[\mathrm{n} / 2] \leq \mathrm{h} \leq \mathrm{n}$ be given, $([\cdot]$ denotes $t i \mathrm{l}, \ldots \ldots$ in: integer function). Let $k=0$ and let $\gamma=\min \left\{\gamma_{\ell} \mid 0 \leq \ell<h\right\}$ be as def $\{: 1: 1$ ind filacen 1 . Then the boundary value problem

$$
\begin{aligned}
& y^{(n)}=f\left(t, y, y^{\prime}, \ldots, y^{(n-1)}\right), \\
& y^{(i)}\left(t_{1}\right)=y_{1+1}, 0 \leq 1 \leq n-h+l-l, \\
& y^{(l)}\left(t_{2}\right)=y_{n-h+(1+1)}^{\prime}, l \leq i \leq h-1,
\end{aligned}
$$

where $a<t_{1}<t_{2}<b, 0 \leq \ell<h$, has a unique solution for tij; ;ijnment of $y_{1} \in R, 1 \leq 1 \leq n$, proviled $t_{2}-t_{1}<\gamma$. Furthermore, this resilit is best possible for the class of all differentlal equations which satisfy the indion (1.?).

$$
\text { P'OFF. Let } a<t_{1}<t_{2}<b \text {, with } t_{2}-t_{1}<\gamma \text {, and } y_{1} \varepsilon R, 1 \leq 1 \leq n \text {, be }
$$
given. We prove the exisitace of solutions for a much larger family of boundary value probleins than those in the statement of the theorem. In fact, we prove the existence of solutions of the two-point problems which belols an the diss of probieill' il Corollary 2. For Induction purposes; we lecange these problems in a lower triangular array,

$$
\begin{array}{cc}
(1,1) & \\
\ddots, 1) & (2.2) \\
\vdots & \vdots \\
(h, 1) & (h, 2) \cdot . \cdot(h, h) ;
\end{array}
$$

where the bountiry value problem for (1) assoclated with the $(\mu, \nu)$-position, 
$1 \leq \nu \leq \mu \leq h$, satisfies

$$
\begin{gathered}
y^{(1)}\left(t_{1}\right)=y_{1+1}, 0 \leq 1 \leq n-v-1, \\
y^{(t)}\left(t_{2}\right)=y_{n-\mu+(1+1)}, \mu-v \leq 1 \leq \mu-1 .
\end{gathered}
$$

Under this arrangement, the boundary value problems for (1.1) along the principal diagonal $(\mu, \mu), 1 \leq \mu \leq h$, are conjugate type problems, whereas the boundary value problems in the statement of this theorem are associated with the entries along the bottom row $(h, v), 1 \leq \nu \leq h$.

By Corollary 2, solutions of all the problems in tihts array are unique on subintervals of length less than $\gamma$. Moreover, by the constraints on $h$ and $k$, it follows that solutions of all conjugate type boundary value problems for (1.1) are unique. Then, it follows from the unlqueness implies existence result of Hartman [16-17] and Klaasen [18] that the c:n] igate boundary value problems, and in part1cular those associated with the entrles on the maln diagonal, have unique solutions. (This is the reason for the constraints on $h$ and $k_{\text {. }}$ ) For existence of solutions of the remaining problems associated with the array, we will use the shooting method coupled with an induction along the subdiagonals on the array.

In that direction, choose any boundary value problem for (1) associated with the first subdiagonal $(\mu, u-1)$, where $2 \leq \mu \leq h$; that 1 , we are concerned with solutions of (1) satisfying

$$
\begin{gathered}
y^{(1)}\left(t_{1}\right)=y_{1+1}, 0 \leq 1 \leq n-\mu, \\
y^{(1)}\left(t_{2}\right)=y_{n-\mu+(1+1)}, 1 \leq 1 \leq \mu-1 .
\end{gathered}
$$

In applying the shopting thethod, let $z(t)$ be the solution of (1) satisfying conditions associated with the $(\mu, \mu)$-position,

$$
\begin{aligned}
& z^{(1)}\left(t_{1}\right)=y_{1+1}, 0 \leq 1 \leq n-\mu-1, \\
& z\left(t_{2}\right)=0, \\
& z^{(t)}\left(t_{2}\right)=y_{n-\mu+(1+1)}, 1 \leq 1 \leq \mu-1,
\end{aligned}
$$

and define $S=\left\{y^{(n-\mu)}\left(t_{1}\right) \mid y(t)\right.$ is a solution of (1) satisfying $y^{(1)}\left(t_{1}\right)=$ $z^{(1)}\left(t_{1}\right), 0 \leq 1 \leq n-u-1$, and $\left.y^{(1)}\left(t_{2}\right)=z^{(1)}\left(t_{2}\right), 1 \leq 1 \leq \mu-1\right\} . \quad S \neq \emptyset$ since $z^{(n-u)}\left(t_{1}\right) \varepsilon S$, and since solutions of the problems corresponding to $(\mu, \mu-1)-$ position are unique, it follows from a standard application of the Brouwer Invariance of Domain Theorem that $S$ is open, (see [20-21] for a typical argument).

We clalm that $S$ is also a closed subset of $R$. Assuming the claim to be false, it follows that there is a limit point $r_{0} \varepsilon \bar{S} \backslash S$. Hence, there exists a strictly monotone sequence $\left\{r_{j}\right\} \subset S$ of numbers converging to $r_{0}$. We may assume without loss of generality that $r_{j} \uparrow r_{0}$. For each $j \geq 1$, let $y_{j}(t)$ denote the solution of (1) given by the definition of $S$ satisfying, 


$$
\begin{aligned}
& y_{j}^{(l)}\left(t_{1}\right)=z^{i(j}\left(t_{1}\right), 0 \leq 1 \leq n-u-1, \\
& y_{j}^{(n-u)}\left(t_{1}\right)=r_{j}, \\
& y_{j}^{(1)}\left(t_{2}\right)=z^{(1)}\left(t_{2}\right), 1 \leq 1 \leq u-1 .
\end{aligned}
$$

From Corollary 2, it follows that, fise each $j \geq 1, y_{j}(t)<y_{j+1}(t)$ on $\left(t_{1}, t_{2}\right]$. Furilienore, since $f$ satisfies the Lipschitz condition (2), it follows that a compactness conditton on sequences of solutions of ( 1 ) is satisfied, (see [10]); froin this compactness condition and the fact that $r_{n} \& 3$, se have that $\left\{y_{j}(t)\right\}$ is not unifornly bounla: mexch compact subinterval of $(a, b)$, and in particular, is not uniformly bounded above on each coinpact subtnterual of $\left[t_{1}, t_{2}\right]$.

Vow let $a(t)$ be the solution of the problem for (1) associated with the $(u-1, u-1)$-postition,

$$
\begin{aligned}
& u^{(1)}\left(t_{1}\right)=y_{1+1}, 0 \leq 1 \leq n-u-1, \\
& u^{(n-11)}\left(t_{1}\right)=r_{0}, \\
& u\left(t_{2}\right)=0, \\
& u^{(1)}\left(t_{2}\right)=y_{n-1+(1+1)}, 1 \leq 1 \leq \mu-2 .
\end{aligned}
$$

It follows that, for some $\delta>0, y_{1}^{(1)}(t)<u^{(1)}(t)$ on $\left(t_{1}, t_{1}+\delta\right), 0 \leq 1 \leq n-\mu$, and et ther $(1)(-1)^{1+1} y_{1}(1)(t)<(-1)^{1+1}{ }_{u}^{(1)}(t)$ on $\left(t_{1}-\delta, t_{1}\right), 0 \leq 1 \leq n-\mu$, when $n-\mu$ is odd, or $(11)(-1)^{1} y_{1}{ }^{(1)}(t)<(-1)^{1} u^{(1)}(t)$ on $\left(t_{1}-\delta, t_{1}\right), 0 \leq 1 \leq n-\mu$, when $n-\mu$ is even. We will assume that $2-\mu$ is odd and also that $t_{2}-\left(t_{1}-\delta\right)<\gamma$.

It follows that there exists a subsequence $\left\{y_{f_{k}}(t)\right\}$ such that, for each $k \geq 1$, $y_{f_{k}}(n-\mu)(t)$ Intersects $u^{(n-\mu)}(t)$ at point $\rho_{k} \varepsilon\left(t_{1}, t_{1}+\delta\right)$ and $y_{j_{k}}{ }^{(n-\mu)}(t)$ Intersects $u^{(n-u)}(t)$ or $y_{1}{ }^{(n-\mu)}(t)$ at a point $\sigma_{k} \varepsilon\left(t_{1}-\delta, t_{1}\right)$ and $\sigma_{k} \uparrow t_{1}$ and $o_{k}+t_{1}$. By choosing successive subsequences and relabeling, we may assume that $t_{1}-\delta<\sigma_{k}<t_{1}<o_{k}<t_{1}+\delta$ are the ftrst points where these intersections occur. Now, if there is an infinite subsequence, which we relabel as $\left\{y_{j_{k}}(t)\right\}$, such that $y_{j_{k}}(n-\mu)\left(\sigma_{k}\right)=y_{1}{ }^{(n-\mu)}\left(\sigma_{k}\right)$, we have that, for each $k,(-1)^{1+1} y_{1}{ }^{(1)}(t)$ $<(-1)^{1+1} y_{f_{k}}(1)(t)<(-1)^{1+1} u(1)(t)$ on $\left(\sigma_{k}, t_{1}\right), 0 \leq 1 \leq n-\mu$. In this case $\lim _{k \rightarrow \infty} y_{j_{k}}(t)\left(\sigma_{k}\right)=y_{1}{ }^{(t)}\left(t_{1}\right), 0<1<n-\mu$. But, it is also the case that $y_{j_{k}}^{(1)}\left(t_{2}\right)=y_{1}{ }^{(1)}\left(t_{2}\right), 1<1<u-1$, and so from the continuous dependence of solutions 
on boundacy conditions of problens assoclated with the ( $u, 11-1)$-position, it follows that $\left\{y_{j_{k}}^{(1)}(t)\right\}$ converge: anlfornly to $y_{l}(t)(t)$ on compact sublntervals of $(a, b)$, .) $\leq 1 \leq n-1$. This is inpossisle, since $y_{j_{k}}^{(n-u)}\left(t_{1}\right)=r_{j_{k}} \rightarrow r_{0}>r_{1}=y_{1}(n-\mu)\left(t_{1}\right)$.

In the case that there $1: 3$ an Infintte sibscilience, whlch we relabel agaln as $\left\{y_{j_{k}}(t)\right\}$, such that $y_{j_{k}}(n-\mu)\left(\sigma_{k}\right)=u^{(n-\mu)}\left(\sigma_{k}\right)$ and $y_{j_{k}}^{(n-\mu)}\left(\rho_{k}\right)=u^{(n-\mu)}\left(\rho_{k}\right), 1 t$ follows that, for each $k,(-1)^{1+1} y_{l}(t)(t)<(-1)^{i+1} y_{j_{k}}(t)(t)<(-1)^{1+1} u^{(1)}(t)$ on $\left(\sigma_{k}, t_{1}\right)$ and $y_{1}{ }^{(t)}(t)<f_{j_{k}}(t)(t) \div 1^{(1)}(t)$ on $\left(t_{1}, n_{k}\right), 0 \leq 1 \leq n-\mu$, and $y_{j_{k}}(n-\mu+1)\left(\tau_{k}\right)=u(n-\mu+1)\left(\tau_{k}\right)$, sone $\tau_{k} \varepsilon\left(\sigma_{k}, \rho_{k}\right)$. It follows that $\lim _{k \rightarrow \infty} y_{j_{k}}(1)\left(\sigma_{k}\right)$ $=u^{(1)}\left(t_{1}\right), 0 \leq 1 \leq n-\mu$, and that $\lim _{k \rightarrow \infty} y_{j_{k}}(n-\mu+1)\left(\tau_{k}\right)=u^{(n-\mu+1)}\left(t_{1}\right)$; it is also the case that $y_{j_{k}}(1)\left(t_{2}\right)=u^{(1)}\left(t_{2}\right), 1 \leq 1 \leq 11-2$. From uniqueness of solutions of boundary value problems for (1) corresponding to tie $(\mu-1, \mu-2)$-position coupled with th arginent similar to the one uset in the proof of the first theorein of [13, Thm. 1] and the fact that $t_{2}-\left(t_{1}-\delta\right)<\gamma$, solutions of this latter type of problem for (1) are unique and thus depend continuously upon boundary conditions; it follows that $\left.{ }^{\left\{y_{j_{k}}\right.}(t)(t)\right\}$ converges uniformly to $u^{(i)}(t)$ on compact subintervals of $(a, b)$, $0 \leq 1 \leq n-1$. In particular, $u^{(u-1)}\left(t_{2}\right)=y_{j_{k}}(\mu-1)\left(t_{2}\right)$, for all $k$, and it then follows that is $(n-\mu)\left(t_{1}\right)=r_{n} \varepsilon s$; doaln, a contradiction.

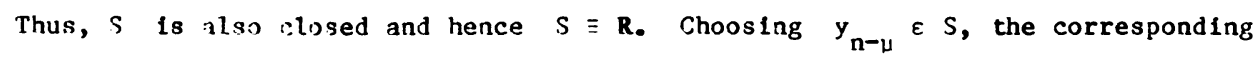
solution of (1) satisfles the boundary value problem corresponding to the $(u, u-1)$-position. Hence, boundary value problens for (l) associated with the first subdlagonal, $(u, u-1), 2 \leq u \leq h$, have unique solutlons.

For the Induction, assume nos tir: ?< $m+1 \leq h$ and that, for each $1 \leq s \leq m$, the boundary value problems for (1) assoclated with the subdiagonals $(u, u-(;-1)), s \leq u \leq h$, have unique solutions.

For $s=n+l$, we now argue that boundary value problems for (1) corresponding to the subdiagonal $(\mu, \mu-m)$, where $m+1 \leq \mu \leq h$, have unique solutions. Choosing any such $(\mu, \mu-m)$, we are concerne 1 diti silutions of (1) satisfying

$$
\begin{aligned}
& y^{(1)}\left(t_{1}\right)=y_{1+1}, 0<1<n-\mu+m-1, \\
& y^{(1)}\left(t_{2}\right)=y_{n-\mu+(1+1)}, m<1<\mu-1 .
\end{aligned}
$$

For the shooting schene here, let $z(t)$ be the solution of (1) corresponding to the 
$(u, \mu-(m-1))-p o s i t$ ton satisfying

$$
\begin{aligned}
& z^{(1)}\left(t_{1}\right)=y_{1+1}, 0<1<1-\mu+m-2, \\
& z^{(m-1)}\left(t_{2}\right)=0, \\
& z^{(1)}\left(t_{-2}\right):=z_{n-\mu+(1+1)}, 1 \div i<\mu-1 .
\end{aligned}
$$

In this case, define $s_{1}=f_{y}^{(n-\mu+m-1)}\left(t_{1}\right) \mid y(t)$ is a solitito: of (1) satisfying $y^{(1)}\left(t_{1}\right)::^{(1)}\left(t_{1}\right), 0<1<n-\mu+m-2$, and $\left.y^{(1)}\left(t_{2}\right)=z^{(1)}\left(t_{2}\right), m<1<\mu-1\right\}$. In a manner analogil: $i$, ins, it san be argued that $S_{1}$ is a noneinpty subset of $R$ which

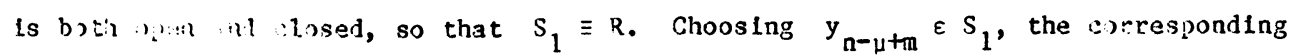
solution of (1) is the dastreil solution. Hence, boundary value problems for (1) assoclatul $\because, 1$, ligonal $(\mu, \mu-m), n+1 \leq \mu \leq h$, have unique solutions.

Therefore, by Induct:on, houndary value problems for (1) 1:is:iated with each entry ta the triangular array have unique soillitol:, 11 gie conclusion of the theorem holds froin the ca: :s arosponilng to the bottom row $(h, v), 1 \leq \nu \leq h$.

Isting niot: is nethods and an induction sintlar to above, one can prove

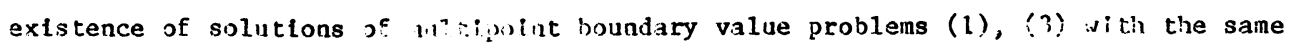
constraints on $h$ and $k$.

THE(OREM 4. Let $\left[n / 2 ! \leq n \leq n\right.$ be given. Let $k=0$ and let $\gamma=n \ell n\left\{\gamma_{\ell} \mid n \leq \ell<h\right\}$ be as defined in Theorem 1 . Then the boundary value problem

$$
\begin{aligned}
& y^{(n)}=f\left(t, y, y^{\prime}, \ldots, y^{(n-1)}\right), \\
& y^{(1)}\left(t_{1}^{\prime}\right)=y_{1+1}, 0 \leq 1 \leq n-h+l-1, \\
& y^{(1)}\left(t_{1}\right)=y_{n-h+(1+1)}, l \leq 1 \leq h-1,
\end{aligned}
$$

where $a<t_{1}^{\prime}<t_{l} \leq \cdots \leq h_{h-1}<h, l \leq l<h$, has a unique solution for any assignment of $y_{1} \varepsilon R, 1 \leq 1 \leq n$, provided $t_{h-1}-t_{1}^{\prime}<\gamma$. This result is best posstble for the class of ilt. lifficential equations which satisfy the Lipschitz condition $(1.2)$.

\section{RHERENCES}

$i$ iaRWAL, R., Best possible length estimates for nonlinear boundfin in: postiems, Bul1. Inst. Math. Acad. Sinica 9 (1931), 169-177.

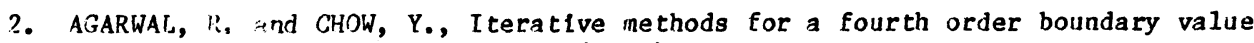
problem, J. Comp. Appl. Math. 10 (1984), 203-217.

3. AGAR!HAL, $\therefore$, and WLLSON, S., On a fourth order inistilary value problem, Utilitas Matin. 265 (1984), 297-310.

4. GINGOLD, H., Thiligeness of solutions of boundary value problems of systems of ordinary difforantiti lations, Pac. J. Math. 75 (1978), 107-136. 
5. GINGOL), !., Int:1-1::; :rtterta for second order nonlinear boundary value problems, J. Yath. Anal. App1. 73 (19:31), 392-410.

5. (GINGOLD, '1. and GUSTAFSON, G., Uniqueness for nth order de la Vallee Pousslu boundary val:1e problems, Applicable Anal. 20 (1985), 201-220.

7. HENDERSiON, J., Best interval lengths for boundary value problens for third order Lipschttz equations, SIAM J. Math. Anal., In press.

3. HENDERSON, .J. and MCGWIER, R., Uniqueness, existence, and optimality for fourth order Lipschitz equations, J. Differential Equations, in press.

9. HENDERSON, J, Boindary value problems for nth ocder i,ipishltz equations, J. Yath. Anal. Appl., In press.

10. JACKSON, L., Existence and uniqeness of solutions of boundary value problems for Lipschitz equatliwi: . Differential Equations 32 (1979), 76-90.

11. JACKSON, I,, Rnindary value problems for Ifipschitz equations, "Differential Equations" (S. Ahmed, M. Paher, A. Lazer, eds.), Academlc Press, New York, $1980,31-50$.

12. MELENTSOVA, YU., A best posstble estinate of the nonosclllation Interval for a Inear differential equation with coefficlents bounded in $\mathrm{L}_{r}$, Diff. Urav. 13 $(1.977), 1776-1786$.

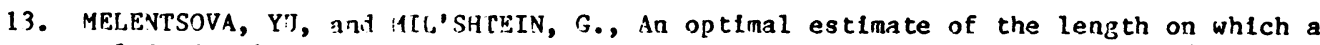
multipolnt houndary value problem possesses a solution, Diff. Urav. 1n (1774), 1630-1641.

14. MELENTSOVA, YU. and MIL'SitPELN, G., Optimal estimation of the nonoscillation intervil for linear ifferential equations with bounded coefficients, Diff. Urav. $17(1931), 2160-2175$.

15. TROCI, T.; Jit the Interval of disconjugacy of linear autonomous differential equations, SIAM J. Math. Anal. 12 (1981), 78-89.

16. HARTMAN, P., Unrestricted n-paraneter families, Rend. Circ. Mat. Palermo (2) 7 $(1958), 123-142$.

17. HARTMAN, P., On n-parameter famllles and interpolation problems for nonlinear nrilary differential equations, Trans. Amer. Math. Soc. 154 (1971), 201-226.

19. KLAASEN, F., Existence theoreins for boundary value problems for nth order ordinary differentlal equations, Rocky Mtn. J. Math. 3 (1973), 457-472.

19. HENDERSON, I. Existence of solutions of right focal point boundary value problems for ordinary differential equations, Nonlinear Anal. 5 (1981), 989-1002.

20. HENDERSON, J., Uniqueness of solutions of right focal p:) int houndary value problems for ordinary differential equations, J. Differential Equation 41 (1981), 218-227.

21. JACKSON, L., Uniqueness of soluttons of boundary value problems for ordinary differentla1. Iititions, SIAM J. Math. App1. 24 (1973), 535-538. 


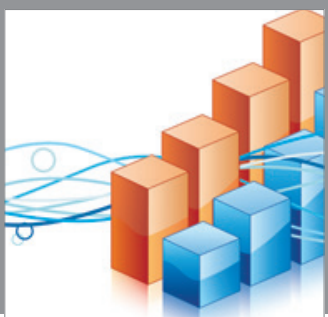

Advances in

Operations Research

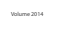

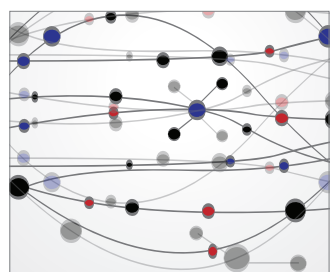

\section{The Scientific} World Journal
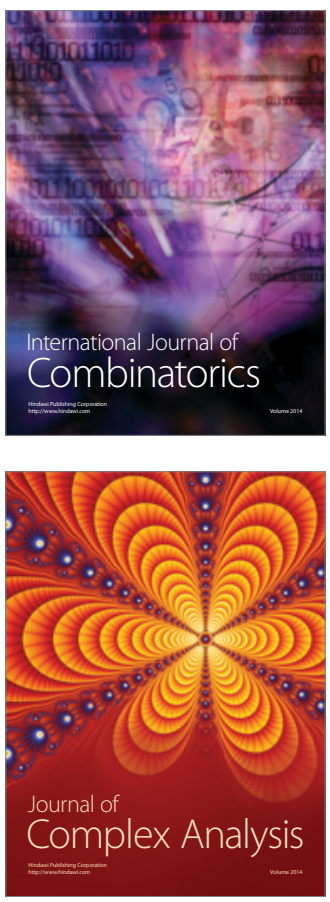

International Journal of

Mathematics and

Mathematical

Sciences
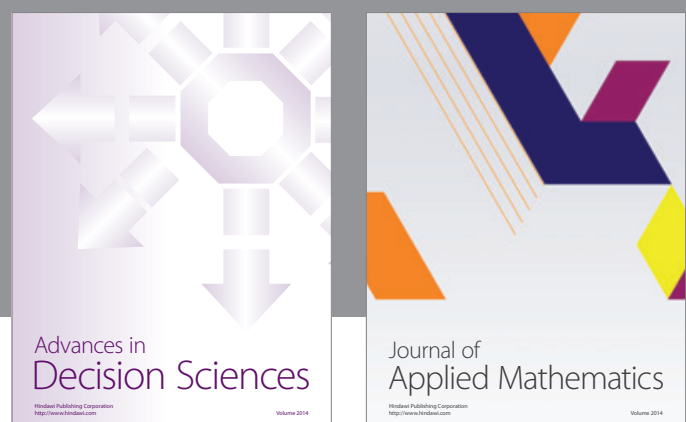

Journal of

Applied Mathematics
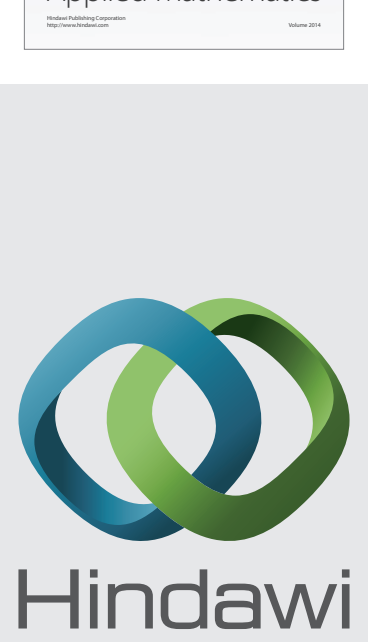

Submit your manuscripts at http://www.hindawi.com
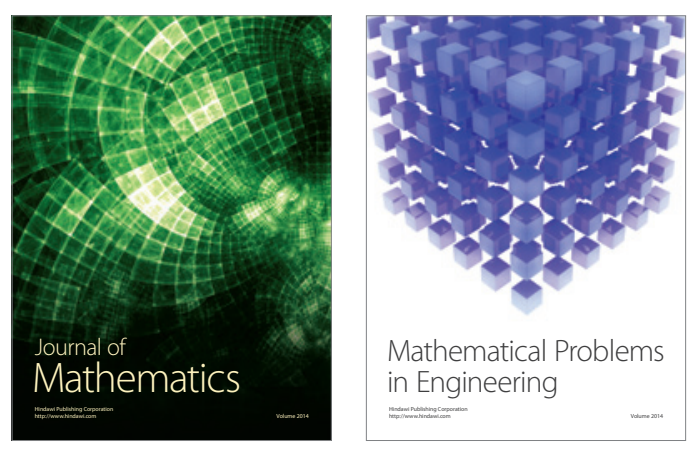

Mathematical Problems in Engineering
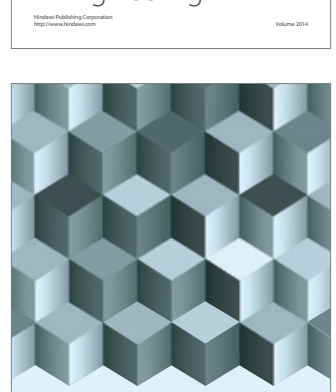

Journal of

Function Spaces
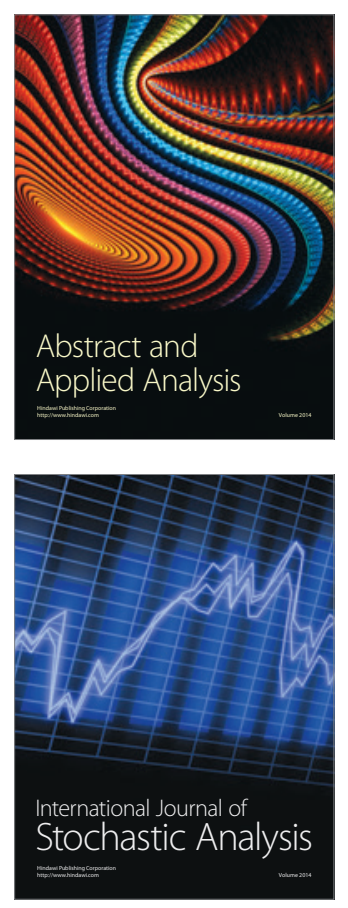

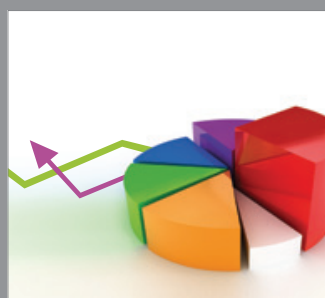

ournal of

Probability and Statistics

Promensencen
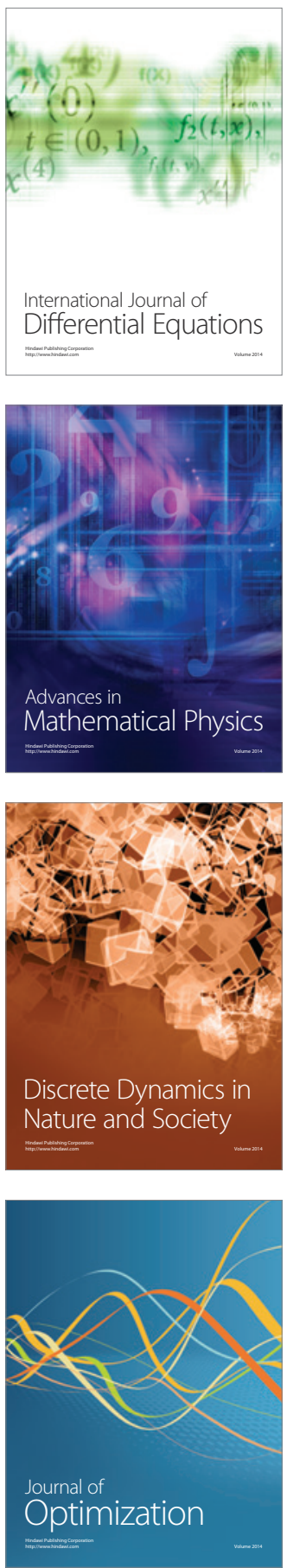